\title{
Prevalence of hypertension in relation to anthropometric indices among secondary adolescents in Mbarara, Southwestern Uganda
}

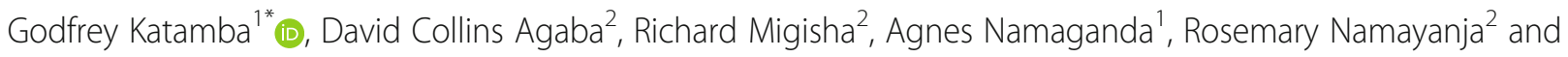
Eleanor Turyakira ${ }^{3}$

\begin{abstract}
Background: Studies investigating the prevalence of hypertension and its correlation with anthropometric indices among adolescents are still scarce compared to those conducted in adults of greater than 40 years. So far, no other study estimating the prevalence and correlates of hypertension among adolescents in Uganda has been found.

Objective: The purpose of this study, therefore, was to asses the prevalence of hypertension and its correlation with anthropometric indices among adolescents in Mbarara Municipality, southwestern Uganda.

Methods: A cross-sectional study was carried out among 616 secondary school adolescents aged 12-19years in Mbarara Municipality, Uganda. Blood pressure and anthropometric indices were determined by standard methods. In the statistical analysis, linear regression analysis was done to assess the relationship between blood pressure and anthropometric indices.
\end{abstract}

Results: Overall prevalence of hypertension among adolescents was at 3.1\% $(n=19)$ while prehypertension was $7.1 \%(n=44)$. There was a statistically significant correlation between blood pressure, neck circumference, waist to hip ratio and body mass index at bivariate analysis. In multivariate analysis for anthropometric indices and sex, only neck circumference remained significantly correlated with blood pressure $(p<0.05)$.

Conclusion: The prevalence of hypertension among adolescents in the study setting was low. An increase in neck circumference results in an increase in blood pressure among adolescents.

Keywords: Adolescents, Hypertension, Prevalence, Anthropometric indices

\section{Introduction}

Hypertension (HTN) is a noncommunicable disease (NCD) which was reported to be most prevalent in Africa at $46 \%$, followed by America at 35\% [1]. Since the year 2000, an increasing upward trend of Htn has been observed [2-4] especially in low- and middle-income

\footnotetext{
* Correspondence: cgmkats13@gmail.com

'Department of Physiology, King Ceasor University, P.O Box 88, Kampala, Uganda

Full list of author information is available at the end of the article
}

countries [1]. Between 60 and 100\% of the disabilityadjusted life-years in sub-Saharan African population is attributed to this burden [5] .

Although hypertension had been previously known as a disease for adults of 40 years or older, it is becoming common in children and adolescents $[6,7]$. In the United States, an estimated $4 \%$ of adolescents between 12 and 19 years are hypertensive [8] compared to $9.5 \%$ of a similar age-group of 13 to 19 year-olds in Africa [9]. Prevalence of hypertension in adolescents is quite 
variable ranging from 3 to $40 \%$ [10-12] in the respective countries such United states of America, India, China, HongKong among othere. However, the majority of these studies included a wide age-range of the participants and hence can not sufficiently estimate the prevalence of Htn in adolescents aged 12-19 years. In Uganda, studies investigating the prevalence of Htn among adolescents strictly are still scarce compared to those in adults. In view of the rising burden of Htn in Africa, epidemiological studies are vital to providing evidence which is essential for planning appropriate interventions. A recent study conducted in both Uganda and Tanzania reported a prevalence of $11 \%$ among adolescents and young people [13]. The national Asthma survey which included participants aged $\geq 12$ years, showed that the prevalence of Htn increased with age [14]. However the majority of the participants in the survey were above 19 years to reliably inform the extent of the burden in adolescents. Without the prevalence data on the silent killer among adolescents, it becomes very difficult to justify the screening for high-risk persons.

An association between adolescent hypertension and obesity was reported in several countries such as China, Korea, HongKong, Nigeria, India among others $[15,16]$. Obesity is a function height and weight, but other anthropometric indices such as neck circumference waist-to-hip ratio may be important determinants of hypertension. Therefore, this study aimed at estimating the prevalence of Htn in relation to the anthropometric indices among secondary school adolescents aged 12-19 years. This was in order to clarify whether targeted screening of this age group for Htn is justifiable in peri-urban low-income settings.

\section{Methods}

\section{Study setting}

The study was conducted in three peri-urban secondary school schools in Mbarara Municipality in southwestern Uganda, between May and November 2018. Mbarara Municipality has up to 25 secondary schools, each with an average of 300 students. The secondary schools are both single-sex and mixed, with provisions for day schooling and boarding sections.

\section{Source population}

This study comprised of both boys and girls aged 12-19 years, attending a secondary school within the municipality. Multistage sampling was used to select the three schools and classes in each school ranged from senior one to senior six. Volunteer sampling was used to arrive at a sample of 616 participants.

\section{Sampling and participant enrolment}

A multistage random sampling method was used. The secondary schools in Mbarara municipality were stratified into three strata based on fees structure in the boarding section; High ( $\geq$ Ugx.650, 000), Middle (Ugx.500,000 - Ugx.650,000) and lower ( $\leq$ Ugx.500,000). One school was selected from each stratum by simple random sampling and from each selected school volunteer participants from Senior one to Senior six were enrolled in the study. Each of the three schools contributed about one-third of the study sample and within the school, each class contributed at least $15 \%$ of the school's allotted number of participants. Students who are physically disabled were excluded because their height could not be easily measured.

\section{Sample size estimation}

The sample size was estimated using the Kish Leslie method of 1965 [17], assuming a prevalence of 10.7\% among secondary school adolescents [12], and 95\% confidence interval within a $3 \%$ error margin. The final sample size was adjusted for an anticipated participant non-response rate of $10 \%$; thus 449 participants were required.

\section{Sociodemographic information}

Socio-demographic data including age, use of alcohol, individual life history of smoking and family history of hypertension were obtained through self-report.

\section{Anthropometric measurements}

These were described in detail by Katamba et al. [18]. Height was measured using a wall mount height board without shoes in centimeters $(\mathrm{cm})$ [2] with the participant shoeless and rear body parts touching the board while the head is facing forward. Weight was measured to the nearest $0.5 \mathrm{~kg}$ using a standard weighing scale (Seca 762, GmbH \& Co. KG, Hamburg, Germany) and participants were encouraged to put on light clothing with no items in the pockets and shoeless [3]. Body mass index (BMI) was computed from the height and weight of each participant as the ratio of the weight of an individual in kilograms to height in square meters and recorded in $\mathrm{kg} / \mathrm{m}^{2}$. Waist circumference (WC) was measured at the midpoint between the lowest border of the rib cage and the top of the lateral border of the iliac crest during minimal expiration the nearest $0.1 \mathrm{~cm}$ by an inelastic flexible measuring tape with the participant standing. Hip circumference (HC) was measured at the greatest horizontal circumference below the iliac crest at the level of the greater trochanter to the nearest $0.1 \mathrm{~cm}$ using an inelastic flexible measuring tape with the participant standing. Waist to hip ratio (WHR) was computed as waist circumference divided by hip 
circumference [4]. Neck circumference (NC) was assessed as a surrogate measure for upper body adipose tissue distribution. It was measured at the level of the laryngeal prominence using an inelastic flexible measuring tape, with the subjects in the standing position and the head held erect and eyes facing forward to the nearest $0.1 \mathrm{~cm}$. The cut-offs for boys and girls were $30.75 \mathrm{~cm}$ and $29.75 \mathrm{~cm}$ respectively [19]. Any values of NC above these cutoffs indicated execss adiposity.

\section{Blood pressure measurement}

Blood pressure was measured using a digital blood pressure machine ((Scian SP-582 Digital BP Monitor, Honsun, Jiangsu, China (Mainland) as described by Katamba et al. [18],. The participant was allowed to seat on a chair with back supported, feet on the floor, arm supported and cubital fossa at heart level after $5 \mathrm{~min}$ of sitting rest without talking $[6,7]$. The cuff was placed at the bare upper arm, 1 inch above the bend of the participant's elbow. It was ensured that the tubing fell over the front center of the arm so that the sensor was correctly placed. The end of the cuff was pulled so that it was evenly tight around the arm. The cuff was placed tight enough so that only two fingertips could be slipped under the top edge of the cuff. It was made sure that the skin did not pinch when the cuff inflated. The participant was asked to remain calm and quiet as the machine begins measuring. The cuff inflated automatically after placing the start button, and then slowly deflated so that the machine took the measurement. When the reading was complete, the monitor displayed the $\mathrm{BP}$ on the digital panel [8]. Three readings were recorded per participant at 5 min' interval. The average of the 2 nd and 3rd SBP and DBP measurement were used as the subject's BP respectively [7]. Those adolescents who had elevated BP in the first session were identified. A remeasurement, using the same procedure was done after 1 week to confirm that BP is truly and constantly elevated.

\section{Blood pressure classification}

Hypertension was defined as BP value $\geq 95$ th percentile of the BP for the gender, age, and height for adolescents less than 18 years while preHTN were defined as SBP/ DBP $\geq 90$ th percentile but less than 95th percentile according to recommendations from the European society of HTN and Fourth report on management of HTN [20, 21]. Adolescents aged 18-19years were considered as adults and HTN among them was classified as average $\mathrm{SBP} \geq 130 \mathrm{mmHg}$ and average $\mathrm{DBP} \geq 80 \mathrm{mmHg}$. Prehypertension was defined as SBP of $120-129 \mathrm{mmHg}$ and DBP $<80 \mathrm{mmHg}$ respectively, according to the 2017 American College of cardiology and American Heart association guidelines on hypertension [22].

\section{Data management and analysis}

All data were recorded on paper forms, entered into Excel (Microsoft office 2013) and analyzed using Stata software version 13.0 (College Station, Texas, USA). Association of Htn with behavioral factors was analyzed using the logistic regression analysis, reporting their odds ratios (OR) and respective 95\% confidence interval (CI). The correlations of blood pressure with anthropometric indices were determined using linear regression analysis; beta coefficients and respective confidence intervals are reported. A $p$-value $<0.05$ was considered statistically significant.

\section{Results \\ Characteristics of study participants}

A total of 616 secondary school adolescents participated in this study, including 212 boys and 404 girls. They were aged between 12 to 19 years with a mean age of 15.6 years and an average BMI of $23.9 \mathrm{kgm}^{-2}$. Females were slightly heavier than boys. The mean systolic blood pressure (SBP) was slightly higher in girls as compared to their counterparts as showed in Table 1.

\section{Prevalence of hypertension among adolescents}

The overall prevalence of hypertension among adolescents was determined as $3.1 \%(n=19)$ while prehypertension was $7.1 \%(n=44)$. Prevalence of prehypertension was lower in girls at $6.4 \%(n=26)$ compared to $8.5 \%(n=$ 18) among the boys. The overall prevalence of systolic hypertension was $5.2 \%(n=32)$ while that of diastolic hypertension was at $9.4 \%(n=58)$. The values in Table 2 shows the proportion of systolic and diastolic hypertension by sex of the participants.

\section{Correlates of hypertension among adolescents}

Having a personal history of taking alcohol and a positive family history of hypertension were significantly associated with hypertension at both bivariate and multivariate analyses. The details of behavioral factors for hypertension are summarised in Table 3.

Analysis of the possible linear relationship between blood pressure measurements and anthropometric indices revealed that both systolic and diastolic blood pressure significantly increased with increase in neck circumference among adolescents. Although a unit increase in body mass index was associated with a significant increase in both systolic and diastolic blood pressure at bivariate analysis, the effects (coefficients) became smaller and non-significant after adjusting for other anthropometric indices. Unexpectedly, a unit increase in waist to hip ratio resulted in a decrease in diastolic blood pressure though it was not statistically significant at multivariate analysis (Table 4). 
Table 1 Characteristics of the study participants by sex

\begin{tabular}{|c|c|c|c|}
\hline \multirow[t]{2}{*}{ Variable } & Girls $(n=404)$ & Boys $(n=212)$ & Total $(n=616)$ \\
\hline & Mean (SD) & Mean (SD) & Mean (SD) \\
\hline Age (years) & $15.8(1.9)$ & $15.3(2.1)$ & $15.6(2.0)$ \\
\hline Weight (kg) & $61.2(8.2)$ & $56.3(8.0)$ & $59.5(8.4)$ \\
\hline Height $(\mathrm{cm})$ & $157.5(7.0)$ & $158.7(8.3)$ & $157.9(7.5)$ \\
\hline Hip Circumference $(\mathrm{cm})$ & $94.5(10.7)$ & $81.5(9.2)$ & $90.0(11.9)$ \\
\hline Waist Circumference $(\mathrm{cm})$ & $71.7(7.9)$ & $68.4(6.7)$ & $70.8(8.0)$ \\
\hline Body Mass Index $\left(\mathrm{kgm}^{-2}\right)$ & $24.7(2.7)$ & $22.4(3.0)$ & $23.9(3.0)$ \\
\hline Neck Circumference (cm) & $30.0(1.6)$ & $30.2(2.8)$ & $30.0(2.1)$ \\
\hline Waist to Hip Ratio & $0.76(0.07)$ & $0.84(0.06)$ & $0.79(0.08)$ \\
\hline Waist to Height Ratio & $0.46(0.05)$ & $0.43(0.04)$ & $0.44(0.05)$ \\
\hline Resting Pulse Rate (bpm) & $76.5(8.4)$ & $73.8(8.0)$ & $75.5(8.3)$ \\
\hline Systolic Blood Pressure $(\mathrm{mmHg})$ & $114.0(7.3)$ & $112.0(8.0)$ & $113.3(9.0)$ \\
\hline Diastolic Blood Pressure $(\mathrm{mmHg})$ & $66.8(8.2)$ & $65.9(8.0)$ & $66.5(8.1)$ \\
\hline
\end{tabular}

$S D$ standard deviation

\section{Discussion}

The current study found that the prevalence of hypertension among secondary school adolescents in the study setting was low. However, the prevalence was more in boys as compared to girls. High prevalences of adolescent hypertension have been reported in populations where the prevalence of obesity was also high [10, 23]. However, in our study setting, the prevalence of obesity was equally low with only $3.4 \%$ of study participants classified as obese.

In our study setting most participants had regular exercise as they walked to and from school, or within their school environment. Studies have shown variations in the prevalence of hypertension by geographical region, level of physical activity as well as socio-economic status. Some adolescents even in a school setting do not participate in co-curricular activities due to a tight academic schedule; they spend much of their time seated and studying week in week out [24]. This denies them the opportunity to do minimal exercises to improve cardiovascular fitness. Others while on holiday, feed on an unhealthy diet which is high in fat content, inadequately feed on fruits and vegetables [25] in addition to watching more television $[26,27]$ and hence becoming overweight

Table 2 Prevalence of hypertension by sex

\begin{tabular}{llll}
\hline BP & Boys; $n(\%)$ & Girls; $\mathrm{n}(\%)$ & Total; $\mathrm{n}(\%)$ \\
\hline Systolic & & & \\
Normal & $197(92.9)$ & $387(95.8)$ & $584(94.8)$ \\
Htn & $15(7.1)$ & $17(4.2)$ & $32(5.2)$ \\
Diastolic & & & \\
Normal & $193(91.0)$ & $365(90.3)$ & $558(90.6)$ \\
Htn & $19(9.0)$ & $39(9.7)$ & $58(9.4)$ \\
\hline Htn Hypertension & & &
\end{tabular}

Htn Hypertension and obese. The diet consumed by the adolescents especially salty food and modified foods like the use of energy drinks [28, 29] and consuming alcohol are also likely causes as was evidenced that some adolescents reported ever use of alcohol. However, the details of how much alcohol drunk and salt consumed were not investigated in this study. Other lifestyle factors such as exposure to persistent academic stress have been identified among adolescents and indicated as risk factors for hypertension [30]. The other probable cause of high blood pressure in adolescents could be persistent hyperactive sympathetic nervous system even at rest [31-33], which increases the smooth muscle tone of the vessels increasing resistance and hence persistently elevating pulse rate, cardiac output and hence elevating blood pressure $[34,35]$. In the current study participants were not screened for any underlying chronic infections like endocrinopathies which have been linked to high blood pressure [36, 37].

Our study findings differ significantly from the findings by several studies which reported prevalences ranging from 3 to $40 \%$. In India, a study reported a prevalence of adolescent hypertension of $21.5 \%$ [38], which was almost 8 times higher than in the current study. In Nigeria, Uwaezuoke and colleagues reported a prevalence of adolescent hypertension of $10.7 \%$ [12] which was almost 4 times that of the current study. This differences may be due to overdiagnosis of blood pressure in the Nigeria study which arising from short-time-interval between measurements and taking all measurements on the same day. In our study, participants with elevated blood pressure on the first contact were re-assessed after 1 week to ensure the accuracy and reliability of the recorded values. Other findings in Uganda from a study which involved 
Table 3 Association of behavioural factors with hypertension

\begin{tabular}{|c|c|c|c|c|c|c|}
\hline \multirow[t]{2}{*}{ History } & \multicolumn{2}{|c|}{ Hypertension } & \multirow[t]{2}{*}{$\mathrm{OR}[\mathrm{Cl}]$} & \multirow{2}{*}{$\begin{array}{l}p- \\
\text { value }\end{array}$} & \multirow[t]{2}{*}{$\mathrm{aOR}[\mathrm{Cl}]$} & \multirow{2}{*}{$\begin{array}{l}p^{-} \\
\text {value }\end{array}$} \\
\hline & Yes $n(\%)$ & Non (\%) & & & & \\
\hline \multicolumn{7}{|c|}{ Ever taken alcohol } \\
\hline Yes & $4(12.5)$ & $28(87.5)$ & $5.4[1.7-17.4]$ & $0.005^{*}$ & $5.1[1.5-17.1]$ & $0.009^{*}$ \\
\hline No & $15(2.6)$ & $569(97.4)$ & & & & \\
\hline \multicolumn{7}{|c|}{ Family History of hypertension } \\
\hline Yes & $7(8.9)$ & $72(91.1)$ & $4.3[1.6-11.1]$ & $0.003^{*}$ & $4.1[1.5-11.0]$ & $0.005^{*}$ \\
\hline No & $12(2.2)$ & $525(97.8)$ & & & & \\
\hline \multicolumn{7}{|c|}{ Ever smoked } \\
\hline Yes & 0 & $11(100.0)$ & Omitted & & Omitted & \\
\hline No & $19(3.0)$ & $586(97.0)$ & & & & \\
\hline
\end{tabular}

participants of 15 years and older, found a prevalence of $27.4 \%$ [11]. However, in this study, $70 \%$ of the participants were aged more than 24 years and so the prevalence estimated in this study cannot generalized to all adolescents in Uganda. Findings from the current study are consistent with other studies of adolescents of adolescents in Houston schools in the USA where McNiece and colleagues reported a prevalence of $3.2 \%$ after three screenings [39] w. Nsanya and colleagues reported a prevalence of $11 \%$ from a study which included adolescents and young adults 12 to 24 years old from Uganda and Tanzania. The difference in the participant's age would have created the difference between the studies. The national Asthma study also reported the prevalence of Htn increased with age in a study which involved all participants aged $\geq 12$ years.

Whereas several studies on Htn among adolescents have singled out childhood obesity as a key driver of adolescent hypertension [6, 40-42], we were unable to demonstrate a significant relationship between BMI and blood pressure in our study. However, we found that neck circumference was a more important predictor of change in blood pressure in the currentr study. In Greece, study findings indicated that all anthropometric indices (AIs) measured including; body mass index (BMI), neck circumference (NC), waist circumference (WC), hip circumference (HC) waist-hip ratio (WHR) and waist to height ratio (WHtR) were correlated with SBP and DBP. Neck circumference was reported to be associated with most CVD risk factors [43]. However, only children of 9 to 13 years were studied and the sample size was too small to draw reliable conclusions. A study in India reported that Htn was associated with a greater mean weight, BMI and waist circumference [44]. In this study, other AIs were not assessed and the sample size was small to make definitive conclusions. A study among Korean adolescents found that high BMI ( $>85$ th percentile) and high waist circumference ( $>90$ th percentile) were positively correlated with high SBP (>90th percentile) in both sexes and high DBP (>90th percentile) in boys [45]. A community-based crosssectional study reported that an increase in SBP and DBP was correlated with an increase in neck circumference and BMI [46]. From the United States of America, findings showed that odds ratios for elevated BPs were

Table 4 Linear regression of anthropometric indices with blood pressure

\begin{tabular}{|c|c|c|c|c|}
\hline \multirow[t]{2}{*}{ Variable } & \multicolumn{2}{|l|}{ Bivariate } & \multicolumn{2}{|c|}{ Multivariate (adjusted; NC,WHR,BMI, sex) } \\
\hline & Beta [CI] & $\overline{p \text {-value }}$ & aBeta [Cl] & $p$-value \\
\hline \multicolumn{5}{|l|}{$\overline{S B P}$} \\
\hline $\mathrm{BMI}\left(\mathrm{kgm}^{-2}\right)$ & $0.31[0.07 ; 0.54]$ & $0.011^{*}$ & $-0.15[-0.38 ; 0.07]$ & 0.184 \\
\hline WHR & $-16.3[-25.7 ;-7.0]$ & $0.001^{*}$ & $-3.65[-13.1 ; 5.83]$ & 0.450 \\
\hline $\mathrm{NC}(\mathrm{cm})$ & $0.61[0.54 ; 0.68]$ & $<0.001^{*}$ & $2.23[1.93 ; 2.54]$ & $<0.001^{*}$ \\
\hline \multicolumn{5}{|l|}{ DBP } \\
\hline BMI $\left(\mathrm{kgm}^{-2}\right)$ & $0.12[-0.09 ; 0.33]$ & 0.265 & $-0.10[-0.32 ; 0.12]$ & 0.373 \\
\hline WHR & $-15.4[-23.8 ;-7.0]$ & $<0.001^{*}$ & $-11.7[-21.1 ;-2.32]$ & $0.015^{*}$ \\
\hline $\mathrm{NC}(\mathrm{cm})$ & $1.25[0.96 ; 1.54]$ & $<0.001^{*}$ & $1.25[0.95 ; 1.56]$ & $<0.001^{*}$ \\
\hline
\end{tabular}

$B M I$ Body mass index, NC Neck circumference, WHR Waist hip ratio, SBP Systolic blood pressure, DBP Diastolic blood pressure, CI Confidence interval, aBeta adjusted beta coefficient; *; significant 
higher in children with wide neck circumference than those with normal neck circumference. BMI and neck circumference were associated with elevated BP in children of 8 to 18 years [47]. Our study was limited by funding and hence could not study the role of endocrinopathies and dyslipidemia in adolescent hypertension. Additionally, data on the correlation between heart rate and blood pressure was not analysed.

\section{Conclusions}

Hypertension was less common among adolescents in this study. Blood pressure was positively correlated with anthropometric indices except for waist-height ratio.

\begin{abstract}
Abbreviations
BP: Blood pressure; NCD: Non communicable disease; BMI: Body mass index; WC: Waist circumference; HC: Hip circumference; NC: Neck circumferebce; SBP: Systolic blood pressure; DBP: Diastolic blood pressure; Cl: Confidence interval; CVD: Cardiovascular disease; WHR: Waist hip ratio; OR: Odds ratio; aOR: Adjusted odds ratio
\end{abstract}

\section{Acknowledgments}

We thank the participants for their support in this work.

\section{Authors' contributions}

GK: Conceptualization of work \& its realization, wrote the manuscript, checked the references, compiled the literature sources, data collection, statistical analysis, and interpretation of data, and wrote the manuscript and is the corresponding author. ET and RN: mentored the conceptualization of work \& its realization, compiling literature sources and statistical analysis, helped in data interpretation, guided manuscript writing, checked the references. DCA, RM and AN: helped in the conceptualization of the work, helped in statistical and data analysis, support to data collection. The author(s) read and approved the final manuscript.

\section{Funding}

This study received no external funding.

\section{Availability of data and materials}

The dataset is available on request from the corresponding author.

\section{Ethics approval and consent to participate}

Ethical approval was obtained from Mbarara University Research ethics committee (IRB No. 18/03-18) and headteachers of the selected secondary schools were contacted for permission before data collection. All potential participants in the study were first sensitized of the study procedures by the research team and the possible benefits and risks explained. All students 1819 years consented for themselves while those between 12 and 17 assented. A few teachers and the nurse within the schools were identified, informed about consent procedures and asked to consent on behalf of each student who was 12-17 years. Participant identification numbers, not names of participants were used in data collection, and no pictures were taken. After the interview and taking measurements, the participants received modest compensation for their participation.

\section{Consent for publication}

Not applicable.

\section{Competing interests}

The authors declare no competing interests in this work.

\section{Author details}

'Department of Physiology, King Ceasor University, P.O Box 88, Kampala, Uganda. ${ }^{2}$ Department of Physiology, Mbarara University of Science and Technology, P.O Box 1410, Mbarara, Uganda. ${ }^{3}$ Department of Community Health, Mbarara University of Science and Technology, P.O Box 1410, Mbarara, Uganda.
Received: 4 February 2020 Accepted: 25 May 2020

Published online: 01 June 2020

\section{References}

1. Mills KT, et al. Global disparities of hypertension prevalence and control. Circulation. 2016;134:441-50.

2. WHO. A global brief on hypertension: silent killer, global public health crisis: World Health Day 2013. (2013).

3. WHO. (World Health Organization; Global health observatory data, 2017).

4. Dreisbach AW. Worldwide estimates of hypertension; 2014.

5. Forouzanfar $\mathrm{MH}$, et al. Global burden of hypertension and systolic blood pressure of at least 110 to $115 \mathrm{~mm} \mathrm{hg,} \mathrm{1990-2015.} \mathrm{Jama.} \mathrm{2017;317:165-82.}$

6. Chen $X$, Wang $Y$. Tracking of blood pressure from childhood to adulthood. Circulation. 2008;117:3171-80.

7. Feber J, Ahmed M. Hypertension in children: new trends and challenges. Clin Sci. 2010;119:151-61.

8. CDC. High Blood Pressure During Childhood and Adolescence. (2018).

9. Noubiap JJ, et al. Prevalence of elevated blood pressure in children and adolescents in Africa: a systematic review and meta-analysis. Lancet Public Health. 2017;2:e375-86.

10. Bell CS, Samuel JP, Samuels JAJH. Prevalence of hypertension in children: Applying the new American Academy of Pediatrics Clinical Practice Guideline. Hypertension. 2019;73:148-52.

11. Musinguzi G, Nuwaha F. Prevalence, awareness and control of hypertension in Uganda. PLoS One. 2013;8:e62236.

12. Uwaezuoke S, Okoli C, Ubesie A, Ikefuna A. Primary hypertension among a population of Nigerian secondary school adolescents: prevalence and correlation with anthropometric indices: a cross-sectional study. Niger J Clin Pract. 2016;19:649-54.

13. Nsanya MK, et al. Prevalence of high blood pressure and associated factors among adolescents and young people in Tanzania and Uganda. J Clin Hypertens (Greenwich). 2019;21:470-8.

14. Lunyera J, et al. Geographic differences in the prevalence of hypertension in Uganda: Results of a national epidemiological study. PLoS One. 2018;13: e0201001.

15. Chorin E, et al. Trends in adolescents Obesity and the association between BMI and blood pressure: a cross-sectional study in 714,922 healthy teenagers. Am J Hypertens. 2015;28:1157-63.

16. Flynn JT, Falkner BE. Obesity hypertension in adolescents: epidemiology, evaluation, and management. J Clin Hypertens. 2011;13:323-31.

17. Kish L. Sampling organizations and groups of unequal sizes. Am Sociol Rev. 1965;30:564-72.

18. Katamba G, et al. Using blood pressure height index to define hypertension among secondary school adolescents in southwestern Uganda. J Hum Hypertens. 2019. https://doi.org/10.1038/s41371-019-0292-x.

19. Patnaik L, Pattnaik S, Rao EV, Sahu T. Validating neck circumference and waist circumference as anthropometric measures of overweight/obesity in adolescents. Indian Pediatr. 2017;54:377-80.

20. Lurbe $E$, et al. Management of high blood pressure in children and adolescents: recommendations of the European Society of Hypertension. J Hypertens. 2009;27:1719-42.

21. Falkner B, et al. The fourth report on the diagnosis, evaluation, and treatment of high blood pressure in children and adolescents. Pediatrics. 2004:114:555-76.

22. Whelton PK. Carey RM, Aronow WS, Casey DE, Collins KJ, Himmelfarb CD, DePalma SM, Gidding S, Jamerson KA, Jones DW, MacLaughlin EJ. 2017 ACC/AHA/AAPA/ABC/ACPM/AGS/APhA/ASH/ASPC/NMA/PCNA guideline for the prevention, detection, evaluation, and management of high blood pressure in adults: a report of the American College of Cardiology/American Heart Association Task Force on Clinical Practice Guidelines. J Am Coll Cardiol. 2018:71(19):e127-248.

23. Aronow WS. Association of obesity with hypertension. Ann Transl Med. 2017:5:350.

24. Fredrikson M, Matthews K. Cardiovascular responses to behavioral stress and hypertension: A meta-analytic review. Ann Behav Med. 1990;12:30-9.

25. Pearson $\mathrm{N}$, et al. Patterns of adolescent physical activity and dietary behaviours. Int J Behav Nutr Phys Act. 2009:6:45.

26. Kelishadi $\mathrm{R}$, et al. Association of physical activity and dietary behaviours in relation to the body mass index in a national sample of Iranian children and adolescents: CASPIAN Study. Bull World Health Organ. 2007:85:19-26. 
27. Rey-Lopez JP, Vicente-Rodríguez G, Biosca M, Moreno LA. Sedentary behaviour and obesity development in children and adolescents. Nutr Metab Cardiovasc Dis. 2008;18:242-51.

28. Seifert SM, Schaechter JL, Hershorin ER, Lipshultz SEJP. Health effects of energy drinks on children, adolescents, and young adults. Pediatrics. 2011; 127:511-28.

29. Azagba S, Langille D, Asbridge MJPM. An emerging adolescent health risk: Caffeinated energy drink consumption patterns among high school students. Prev Med. 2014;62:54-9.

30. Mucci N, et al. Anxiety, stress-related factors, and blood pressure in young adults. Front Psychol. 2016;7:1682

31. Sorof JM, Poffenbarger T, Franco K, Bernard L, Portman RJ. Isolated systolic hypertension, obesity, and hyperkinetic hemodynamic states in children. J Pediatr. 2002;140:660-6.

32. Parati $G$, Esler $M$. The human sympathetic nervous system: its relevance in hypertension and heart failure. Eur Heart J. 2012;33:1058-66.

33. Guzzetti S, et al. Sympathetic predominance an essential hypertension: a study employing spectral analysis of heart rate variability. J Hypertens. 1988; 6:711-7.

34. Grassi G, Mark A, Esler M. The sympathetic nervous system alterations in human hypertension. Circ Res. 2015;116:976-90.

35. Kalil GZ, Haynes WG. Sympathetic nervous system in obesity-related hypertension: mechanisms and clinical implications. Hypertens Res. 2012;35:4

36. Hall JE. Guyton and Hall Textbook of Medical Physiology E-Book. Elsevier Health Sciences; 2015.

37. Sembulingam K, Sembulingam P. Essentials of medical physiology. JP Medical Ltd; 2012.

38. Sundar JS, et al. Prevalence and determinants of hypertension among urban school children in the age group of 13-17 years in, Chennai, Tamilnadu. Epidemiol. 2013;3:2161-1165.1000130.

39. McNiece KL, et al. Prevalence of hypertension and pre-hypertension among adolescents. J Pediatr. 2007;150:640-4. e641.

40. Daniels S. Complications of obesity in children and adolescents. Int J Obes. 2009;33:560-5.

41. Hirose $\mathrm{H}$, et al. The obese gene product, leptin: possible role in obesityrelated hypertension in adolescents. J Hypertens. 1998;16:2007-12.

42. Kotchen T, Obesity-Related A. Hypertension? Hypertension. 2008:52:801-2.

43. Androutsos $\mathrm{O}$, et al. Neck circumference: a useful screening tool of cardiovascular risk in children. Pediatr Obes. 2012;7:187-95.

44. Srivastava A, Kandpal S, Negi K, Srivastava A. Prevalence and risk factor of hypertension among medical college students, HIMS, Dehradon. Indian J Prev Soc Med. 2012:1:43

45. Song $\mathrm{Y}-\mathrm{H}$. The association of blood pressure with body mass index and waist circumference in normal weight and overweight adolescents. Kor J Pediatr. 2014;57:79-84

46. Rajagopalan A, Balaji N. Association of neck circumference and obesity with blood pressure among adolescents in urban and rural population in North Tamil Nadu J J Nat Sci Biol Med. 2017:8:144.

47. Nafiu O, Zepeda A, Curcio C, Prasad Y. Association of neck circumference and obesity status with elevated blood pressure in children. J Hum Hypertens. 2014;28:263-8.

\section{Publisher's Note}

Springer Nature remains neutral with regard to jurisdictional claims in published maps and institutional affiliations.

Ready to submit your research? Choose BMC and benefit from:

- fast, convenient online submission

- thorough peer review by experienced researchers in your field

- rapid publication on acceptance

- support for research data, including large and complex data types

- gold Open Access which fosters wider collaboration and increased citations

- maximum visibility for your research: over $100 \mathrm{M}$ website views per year

At BMC, research is always in progress.

Learn more biomedcentral.com/submissions 